\title{
Chemical Analysis and Inhibition Reactions of the Group and Type Antigens of Group F Streptococci
}

\author{
BY J. M. N. WILLERS, M. F. MICHEL, MARIA J. SYSMA AND \\ K. C. WINKLER \\ Laboratory of Microbiology, University of Utrecht, Netherlands
}

(Received 28 January 1964)

\begin{abstract}
SUMMARY
Qualitative and quantitative analyses of formamide extracts of group F streptococci revealed rhamnose, glucose, galactose, glucosamine and galactosamine as main components. The rhamnose content was high. Streptococci, carrying a type antigen in the cell wall, excreted into the medium also a polysaccharide with the same serological activity. These soluble polysaccharides contained no muramic acid, small amounts of rhamnose, but had a high glucosamine and mannose content. Column chromatography on DEAE-cellulose revealed the formamide extracts to be heterogeneous. Over $90 \%$ of the serological activity could be recovered in one of the fractions. Inhibition reactions of the quantitative precipitation with a number of simple sugars gave indications about the composition of the determinant groups of group and type antigens. Rhamnose was inactive in all cases. The determinant group of the group $\mathrm{F}$ antigen is at least a disaccharide with a $\beta$-glucosidic moiety. The determinants of the type antigens I and II probably contain N-acetyl-galactosamine. There is evidence for a second determinant in type antigen II. The determinants of type antigens III and V contain a $\beta$-glucosidic moiety, that of antigen IV a $\beta$-galactosidic moiety.
\end{abstract}

\section{INTRODUCTION}

A large number of indifferent (no $\alpha$ - or $\beta$-haemolysis) and haemolytic streptococci isolated from dental root canals have been shown to belong to the serological groups $F$ and $G$ of the Lancefield system (Winkler \& van Amerongen, 1959). Ottens (1961) and Ottens \& Winkler (1962) found that some of the group F strains contained several type antigens apart from the group antigen. These type antigens were called I, II, III, IV and V. Other strains containing merely the group antigen but no known type antigen were indicated as F. O. Strains which contained a type antigen but no group antigen were indicated as $\mathrm{O}$. I, O. II and $\mathrm{O}$. IV. The type antigens III and V were never found separately from the group antigen. Ottens \& Winkler (1962) demonstrated that type antigen I occurred in indifferent and haemolytic strains of group G; the type III antigen occurred in indifferent strains of group $\mathrm{C}$. Both the group antigen $\mathrm{F}$ and the type antigens were shown to be carbohydrates.

Cummins \& Harris (1956) have shown that the cell walls of group F streptococci contain the following sugars and amino sugars: glucose, galactose, rhamnose, glucosamine, galactosamine and muramic acid. In the present paper analyses of cell walls and cell wall antigens, obtained by formamide extraction of the afore- 
mentioned strains are presented. During the investigation it appeared that some of the strains containing type antigens in the cell wall also excreted antigen in the medium. These soluble antigens with the same serological activity were also analysed. The results of qualitative and quantitative analysis of the group and type antigens were compared. On an anion exchange column, the formamide extracts proved to be heterogeneous. The consequence of this is discussed. The inhibition by simple sugars of the quantitative precipitation of the antigens F, I, II, III, IV and V with their antibodies provided evidence that the determinant groups of these antigens are different and contain different sugars.

\section{METHODS}

Culture conditions. All strains were grown in 4 l. Todd Hewitt Broth enriched with $0.2 \%$ glucose for $24 \mathrm{hr}$ at $37^{\circ}$. To obtain polysaccharides excreted in the medium, the strains were grown without additional glucose to reduce autolysis. Cells were obtained by centrifugation at $4000 \mathrm{rev}$./min., washed three times with distilled water and finally centrifuged at $17,000 \mathrm{rev} . / \mathrm{min}$.

Isolation of cell ralls. Cell walls were isolated as described by Michel \& Gooder (1962) with minor modifications. Enzyme treatment of the disintegrated bacteria was restricted to trypsin $\left(1 \mathrm{mg} . / \mathrm{ml}\right.$. for $2 \mathrm{hr}$ at $37^{\circ}$, followed by another $0.5 \mathrm{mg} . / \mathrm{ml}$. for $1 \mathrm{hr}$ ).

Formamide extraction. The group- and/or type-specific polysaccharide was extracted from the bacteria with formamide according to Fuller (1938). As a final step the acetone precipitated material was dissolved in $20 \mathrm{ml}$. of distilled water and dialysed for $48 \mathrm{hr}$ against several changes of distilled water at $4^{\circ}$. A small precipitate which often appeared during dialysis inside the bag was discarded.

Isolation of the polysaccharides excreted in the medium. The polysaccharide excreting strains O. I, O. II, F. II, F. III, O. IV and F. V were grown as indicated. After centrifugation at $4000 \mathrm{rev}$./min. for $40 \mathrm{~min}$. the supernatant of a culture was sterilized for $20 \mathrm{~min}$. at $120^{\circ}$. The volume of the medium was then reduced to onetwentieth by dialysis against Carbowax (polyethyleneglycol 4000). The proteins were precipitated from the concentrate by addition of two and a half volumes $96 \%$ alcohol containing $1 \%$ concentrated hydrochloric acid and discarded by centrifugation. The crude polysaccharide was precipitated from the supernatant by the addition of an equal volume of acetone. After centrifugation the precipitate was dissolved in distilled water and extracted with an equal volume of $25 \%(v / v)$ trichloracetic acid. Undissolved impurities were centrifuged out and the polysaccharide reprecipitated by adding ten volumes of acetone, redissolved in distilled water and finally dialysed for $48 \mathrm{hr}$ at $4^{\circ}$ against several changes of distilled water.

Purification of antigen by the corresponding antiserum. Type $\mathrm{V}$ antigen was precipitated from the $F . V$ formamide extract by adding type $V$ antiserum at the optimum quantity, as determined by the quantitative precipitation, described below. The precipitate was centrifuged out after $24 \mathrm{hr}$, washed three times with cold saline and dissolved in $0.01 \mathrm{~N}-\mathrm{NaOH}$. An equal volume of $25 \%(\mathrm{v} / \mathrm{v})$ trichloracetic acid was added to precipitate the antibody proteins. The antigen in the supernatant was isolated in the same manner as that described for the isolation of the polysaccharides excreted in the medium. 
Hydrolysis conditions. For the qualitative sugar analysis of cell walls (20 mg. of dry material), Fuller extracts $(5 \mathrm{ml}$.) or polysaccharides isolated from the medium ( $5 \mathrm{ml}$.), and the material was hydrolysed in a final concentration of $2 \mathrm{~N}_{2} \mathrm{SO}_{4}$ at $100^{\circ}$ for $2 \mathrm{hr}$. After cooling, the hydrolysates were neutralized with a saturated solution of $\mathrm{Ba}(\mathrm{OH})_{2}$, centrifuged and the sediment washed once with distilled water. The combined supernatants were dried at $45^{\circ}$ in vacuo and redissolved in $0.35 \mathrm{ml}$. distilled water.

For the quantitative analysis of formamide extracts $(5 \mathrm{ml}$.) and polysaccharides isolated from the medium ( $5 \mathrm{ml}$.), the material was hydrolysed in a final concentration of $4 \mathrm{~N}-\mathrm{HCl}$ at $100^{\circ}$ for $3 \mathrm{hr}$. The hydrolysates were then evaporated three times in vacuo and dissolved in a small amount of distilled water.

Paper chromatography. Amino sugars and sugars were separated by two dimensional chromatography on Whatman no. 1 paper $(40 \times 30 \mathrm{~cm}$. $) . \mathrm{N}-\mathrm{Butanol}+$ acetic acid + water $\left(60+10+20\right.$ by vol.) and $2 \cdot 4-2 \cdot 5$ lutidine redistilled at $154^{\circ}+$ water $(65+35$ by vol.) were used as solvent for 42 and $20 \mathrm{hr}$ respectively. After drying the papers were sprayed with silver nitrate reagent as described by Trevelyan, Procter \& Harrison (1950). Using as markers all the sugars and amino sugars which could reasonably be expected (Slade \& Slamp, 1962) good separation with this system was obtained except for the $\mathrm{N}$-acetyl derivatives of glucosamine and galactosamine.

Determination of sugars and amino sugars. Hydrolysates of formamide extracts and of polysaccharides isolated from the medium were put on a Zeokarb 225 column $\mathrm{H}^{+}$form $(0.8 \times 40 \mathrm{~cm}$.) and a sufficient amount of distilled water was used to eluate the hexoses and rhamnose. Glucosamine and galactosamine were then eluated and separated on a fraction collector with $0.33 \mathrm{~N}-\mathrm{HCl}$ (Gardell, 1953). Amino sugars were determined with the Elson and Morgan reaction as modified by Rondle \& Morgan (1955). The hexoses and rhamnose were determined in the water eluate of the Zeokarb column. Glucose was determined with glucose oxidase, as described by Hugett \& Nixon (1957), rhamnose with the thioglycollic acid/sulphuric acid reaction according to Gibbons (1955), mannose as described by Dische, Shettles \& Osnos (1949). The galactose determination was corrected for the presence of the previously determined amounts of glucose and rhamnose; the mannose determination was corrected for the presence of the previously determined amounts of glucose, galactose and rhamnose.

Anion exchange chromatography. Column chromatography of formamide extracts was carried out on DEAE-cellulose (Serva, Heidelberg), as described by Kündig, Neukom \& Deuel (1961) for cereals. The column was eluted with the following solutions : distilled water, phosphate buffer $\mathrm{pH} \mathrm{7,} \mathrm{0.0175} \mathrm{M} \mathrm{(PB),} \mathrm{PB} \mathrm{+} \mathrm{0.1} \mathrm{M-NaCl,}$ $\mathrm{PB}+\mathbf{0} \cdot 25 \mathrm{M}-\mathrm{NaCl}, \mathbf{0} \cdot 1 \mathrm{~N}-\mathrm{NaOH}$. The dry weight of the eluted fractions was determined and the serological activity was measured by quantitative precipitation.

Quantitative precipitation inhibition. Sera were prepared in rabbits by four weekly subcutaneous injections of heat-killed streptococci followed by twelve intravenous injections on 4 days in each of 3 subsequent weeks. After an interval of 2 months, booster injections were given followed by bleeding 8-10 days later. Quantitative precipitations were carried out as described by McCarty \& Lancefield (1955). Apart from the sugars mentioned in Table 4, the following sugars were used in the inhibition reactions: rhamnose, mannose, $\alpha$-methyl-galactoside, $\alpha$-methyl-glucoside, 
2-desoxy-glucose, phenyl- $\beta$-glucoside, 3-o-methyl-glucoside, $\mathrm{N}$-acetyl-glucosamine, maltose, trehalose, turanose, saccharose, raffinose, melezitose, stachyose and galactitol. The reactions were carried out by incubating $8 \mathrm{mg}$. of the sugars with the diluted antiserum during $1 \mathrm{hr}$ at $37^{\circ}$. Thereafter the antigen was added and the incubation was continued for $1 \mathrm{hr}$ at $37^{\circ}$ and overnight at $4^{\circ}$. Of the sugars giving more than $10 \%$ inhibition, inhibition-curves for amounts ranging from 10 to $90 \mu$ mole of sugar were determined.

\section{RESULTS}

The data resulting from the qualitative analyses of the hydrolysates of the cell walls, the formamide extracts and the polysaccharides excreted in the medium are given in Table 1. Only the cell walls contained muramic acid. Rhamnose was found in the cell walls and in the formamide extracts, but the rhamnose spots were definitely less pronounced in the hydrolysates of the excreted polysaccharides. On the other hand, the last material had a high content of mannose, whereas this sugar was almost absent in both cell walls and formamide extracts. The hydrolysates of the cell wall have a high glucosamine content which is in part derived from the mucopeptide complex. The high glucosamine content of all polysaccharides excreted into the medium distinguishes them from those in the formamide extracts. In the latter case the amount of glucosamine varied with different strains. Most of the hydrolysates contained galactosamine and the hexoses glucose and galactose. It is remarkable that in the case of $\mathbf{F} . \mathrm{O}$ both the glucosamine and the galactose content are nil or low. Though hydrolysis conditions were kept constant the frequent presence of $\mathrm{N}$-acetyl-hexosamine spots except in the hydrolysates of the cell walls points to differences in acid sensitivity of the materials examined.

Finally all chromatograms showed a varying amount of a number of five rather weak spots named $\boldsymbol{A}$ to $\boldsymbol{D}$ and $\boldsymbol{Z}$. Noteworthy is the fact that the strongest spot $(A)$ corresponded to a substance which was split off from the group antigen $\mathbf{F}$ only and was never seen in hydrolysates prepared from type antigens I, II and IV. The unknown $Z$ was substantially different from the other ones giving a reddish brown colour with the silvernitrate spray and having high velocity in both solvents (Rg. butanol-acetic acid 3·00, Rg. lutidine 1·27).

Quantitative analyses are generally in agreement with the qualitative ones, taking in mind that the conditions of hydrolysis were different. As the excreted polysaccharides were not yet sufficiently pure (maximum $25 \%$, based upon saccharide content), only the formamide extracts were studied (Table 2). Rhamnose was always present in large amounts. In contradistinction to the results of qualitative chromatography mannose was found in all the hydrolysates tested, except in F. O. As the demonstration of small amounts of mannose on the chromatogram is relatively insensitive the results of the quantitative analysis should prevail. As the quantitative determination of mannose is the least reliable one, in view of the corrections for other sugars, low values in Table 2 should be distrusted. In the antigens F, F. III and F. V low glucosamine contents were found. These might be derived from contaminating mucopeptide. The antigen $\mathbf{F}$ had by far the simplest composition. It consisted mainly of rhamnose, galactosamine and glucose. In addition a small amount of galactose was found to be present. The composition of 


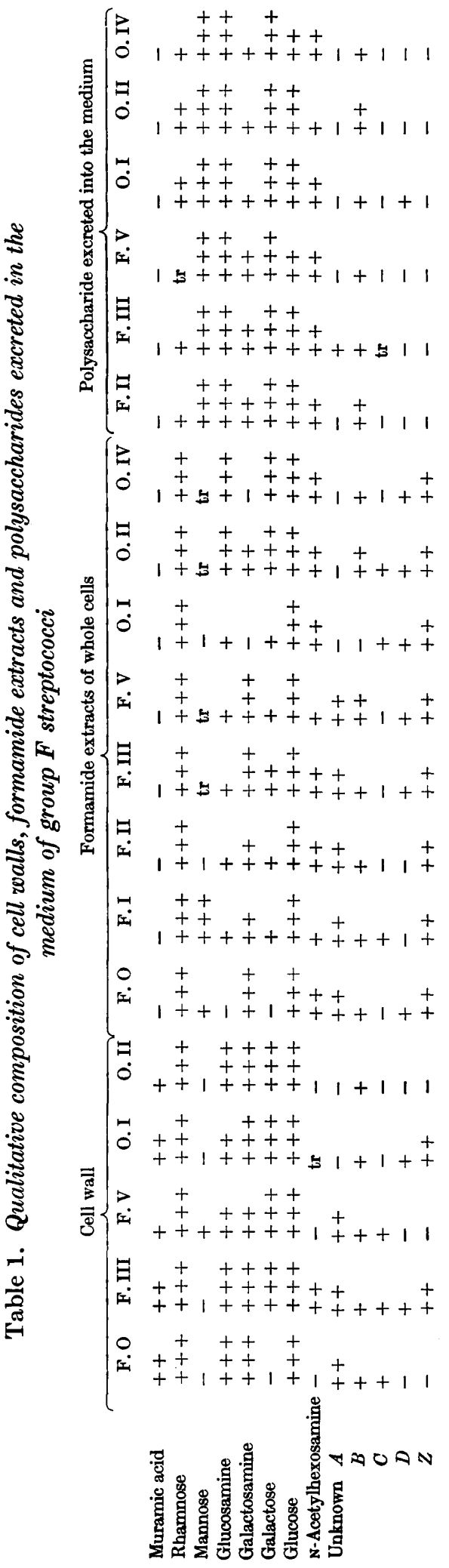


the isolated antigen $\mathbf{V}$ was also very simple. It consisted mainly of glucose and galactose and had a low rhamnose and glucosamine content.

Formamide extracts hydrolysed by hydrochloric acid did not contain N-acetylhexosamines, indicating that the hydrolysis was complete under these conditions. The total weight of sugars and amino sugars after hydrolysis of the formamide extracts amounted to only $\mathbf{4 0} \%$ of the dry weight of the unhydrolysed material. The low sugar yield has to be ascribed to impurities of non-saccharidelike nature and to some destruction by acid hydrolysis.

\section{Table 2. Quantitative composition of formamide extracts of group $F$ streptococci}

The figures give the percentages of the sugars calculated on the total recovery of each strain.

\begin{tabular}{|c|c|c|c|c|c|c|}
\hline $\begin{array}{c}\text { Name of } \\
\text { strain }\end{array}$ & Rhamnose & Mannose & Glucosam & ctosamine & Galactose & Glucose \\
\hline F. $O$ & $48 \cdot 2$ & 0 & $\mathbf{1}$ & 27 & $\mathbf{3}$ & $20 \cdot 6$ \\
\hline F. I & $17 \cdot 3$ & $20 \cdot 5$ & $18 \cdot 9$ & $17 \cdot 3$ & 13 & 13 \\
\hline F. II & $55 \cdot 3$ & $5 \cdot 9$ & 4.5 & $11 \cdot 9$ & $14 \cdot 6$ & $4 \cdot 5$ \\
\hline F. III & $36 \cdot 4$ & $12 \cdot 1$ & $0 \cdot 8$ & $14 \cdot 6$ & $24 \cdot 3$ & $11 \cdot 7$ \\
\hline F. V & 50 & Not done & 1 & 20 & 12 & 17 \\
\hline O. I & $33 \cdot 6$ & 7 & $13 \cdot 4$ & $4 \cdot 2$ & $16 \cdot 8$ & $25 \cdot 2$ \\
\hline O. II & $30 \cdot 4$ & 15 & 26 & $4 \cdot 3$ & 19 & $5 \cdot 2$ \\
\hline O. IV & $32 \cdot 8$ & Not done & $21 \cdot 8$ & o & $\mathbf{3 5} \cdot 8$ & 4.5 \\
\hline $\mathrm{AgV}^{*}$ & $4 \cdot 6$ & Not done & 4 & $\mathbf{0}$ & $57 \cdot 2$ & $34 \cdot 3$ \\
\hline
\end{tabular}

* This polysaccharide was obtained by precipitating the $V$ antigen from a $F$. $V$ formamide extract by anti $V$ serum. The $V$ antigen was isolated from the precipitate.

Table 3. Fractionation of the formamide extracts of strains $O . I$ and $O . I I$ on $a$ DEAE-cellulose column

The serological activity is determined by a quantitative precipitation reaction. The number of units is the product of the reciprocal of the dilution at the optimum, and the volume of the antigen solution added.

\begin{tabular}{|c|c|c|c|c|}
\hline \multirow[b]{2}{*}{ Eluted with } & \multicolumn{2}{|c|}{ Formamide extract $O$. I } & \multicolumn{2}{|c|}{ Formamide extract 0 . II } \\
\hline & $\begin{array}{l}\text { Weight of } \\
\text { the fraction } \\
\text { (mg.) }\end{array}$ & $\begin{array}{c}\text { Serological } \\
\text { activity } \\
\text { (units) }\end{array}$ & $\begin{array}{l}\text { Weight of } \\
\text { the fraction } \\
\text { (mg.) }\end{array}$ & $\begin{array}{c}\text { Serological } \\
\text { activity } \\
\text { (units) }\end{array}$ \\
\hline Distilled water & 342 & 1600 & $\mathbf{2 6 7}$ & 800 \\
\hline PB* & 342 & $<10$ & 313 & $<10$ \\
\hline $\mathrm{PB}+0 \cdot 1 \mathrm{M}-\mathrm{NaCl}$ & 187 & $<10$ & 154 & $<10$ \\
\hline $\mathrm{PB}+0.25 \mathrm{~m}-\mathrm{NaCl}$ & 91 & $<10$ & 66 & $<10$ \\
\hline $0.1 \mathrm{~N}-\mathrm{NaOH}$ & 124 & $<10$ & 162 & $<10$ \\
\hline
\end{tabular}

* PB, Phosphate buffer 0.0175 м (pH 7).

Column chromatography. The low percentages of monosaccharides recovered raised questions about the purity of the formamide extracts. Fractionation on a DEAE-cellulose column revealed that at least 5 fractions could be obtained. Table 3 shows in a typical experiment the heterogeneity of the formamide extracts of strains $O$. I and $O$. II. In both cases most of the serological activity was found in the distilled water eluate. 


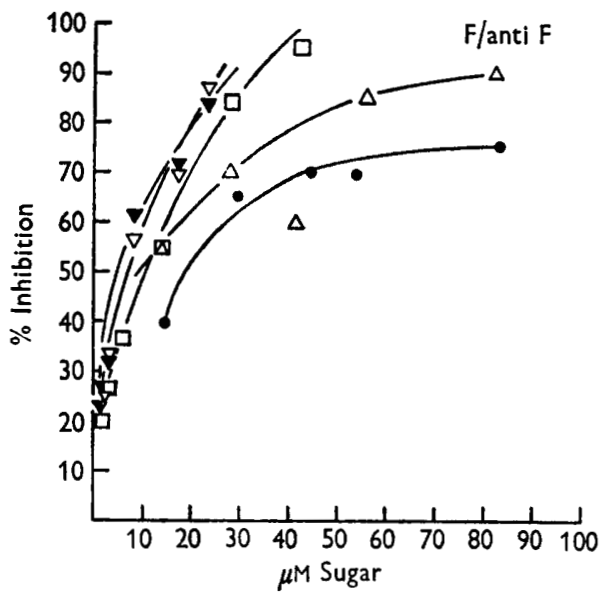

Fig. 1

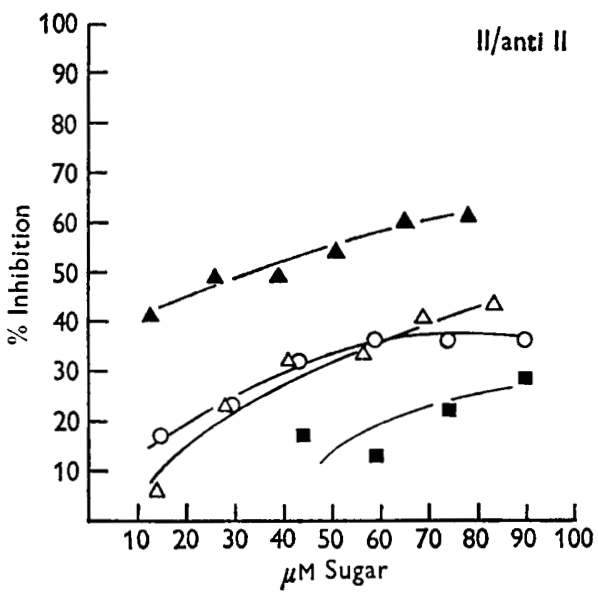

Fig. 3

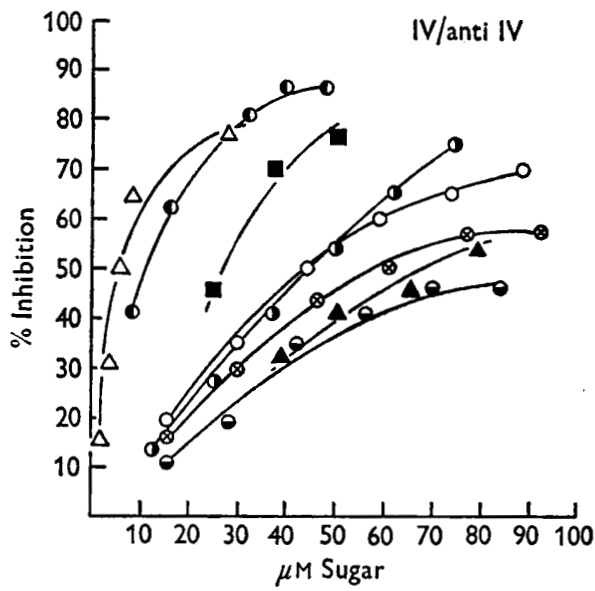

Fig. 5

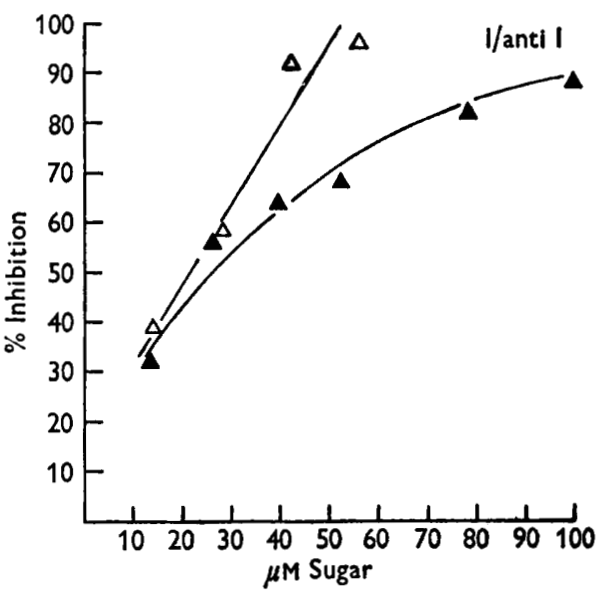

Fig. 2

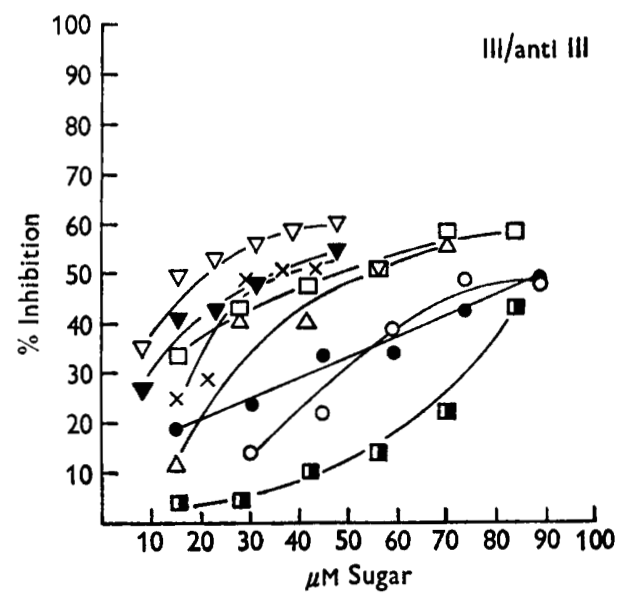

Fig. 4

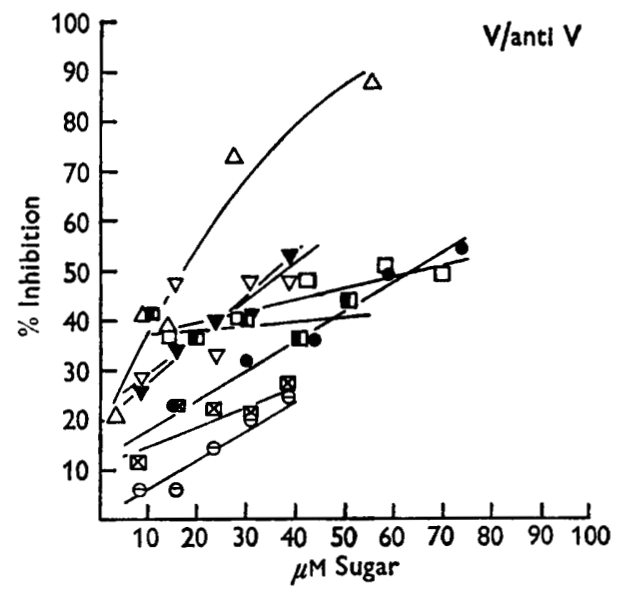

Fig. 6

Figs. 1-6. Inhibition reactions of quantitative precipitations by the following sugars : $\boldsymbol{O}$. Glucose; $O$, galactose; $O$, glucosamine; $\boldsymbol{\Delta}$, galactosamine; $\Delta, \mathbf{N}$-acetylgalactosamine; $\square, \alpha$-methyl-glucoside; $\square, \beta$-methyl-glucoside; $\mathbf{0}$, phenyl- $\beta$ glucoside; $\ominus, \alpha$-methyl-galactoside; $\otimes, 2$ desoxy-galactose; $\Delta$, N-methyl-glucamine; $\nabla$, cellobiose; $\nabla$, gentiobiose; $\Phi$, lactose ; $\times$, melibiose ; $\ominus$, maltose; $\otimes$, trehalose. 
Quantitative precipitation inhibition analysis. As antigens in these reactions, the eluates from the DEAE-cellulose column showing the highest serological activity were used. In the case of formamide extracts of strains F. O, O. I, O. II and F. III the distilled water fractions were used. For the serology of O. IV and F. V the distilled water fractions showed no activity and the next two fractions were used. Figs. 1-6 give the inhibitions of the serological reactions between the antigens $F$, I, II, III, IV, V and their corresponding antisera by the sugars that were present in the formamide extracts. Several derivatives of the sugars were also tested. The figures give only the inhibitions by sugars which in preliminary experiments inhibited the antigen-antibody reaction more than $10 \%$ at a level of $8 \mathrm{mg}$. sugar in $0.2 \mathrm{ml}$. serum or serum dilution. The other sugars tested (see Methods) gave less than $10 \%$ inhibition. The implications of these data for the composition of the determinant groups of the different polysaccharides examined will be discussed in the next section.

Table 4. Inhibitions by simple sugars of the quantitative precipitation between the $F$, $I, I I, I I I, I V, V$ antigens and their respective antisera

The values in the table give the $50 \%$ inhibition expressed in $\mu \mathrm{M}$ sugar.

\begin{tabular}{|c|c|c|c|c|c|c|}
\hline & & & & & & \\
\hline & $\mathbf{F}$ & I & II & III & IV & $\mathbf{V}$ \\
\hline Glucose & 19 & . & . & 90 & . & 65 \\
\hline Galactose & . & . & . & . & 45 & . \\
\hline Glucosamine & . & . & . & . & 45 & . \\
\hline Galactosamine & . & . & . & . & 27 & . \\
\hline $\mathrm{N}$-Acetyl-galactosamine & . & 27 & 35 & . & 67 & . \\
\hline$\beta$-Methyl-glucoside & 13 & . & . & 46 & . & 67 \\
\hline 2-Desoxygalactose & . & . & . & $\cdot$ & $\mathbf{5 9}$ & . \\
\hline N-Methyl-glucamine & 10 & 22 & . & $\mathbf{5 4}$ & 6 & 17 \\
\hline Cellobiose & 6 & . & . & 34 & . & 37 \\
\hline Gentiobiose & 7 & . & . & 18 & . & 38 \\
\hline Lactose & . & . & . & . & 10 & . \\
\hline Melibiose & . & . & . & 35 & . & . \\
\hline
\end{tabular}

\section{DISCUSSION}

Results of the qualitative analysis of the different materials as given in Table 1 are in general agreement with the results obtained for streptococci by other workers (Cummins \& Harris, 1956; Slade \& Slamp, 1962).

A peculiar observation was the excretion of a serologically active polysaccharide into the medium by some of the strains. Quantitative analysis of this material and comparison with the data obtained in the analysis of the formamide extracts awaits further purification. Because these polysaccharides are undegraded they may be expected to give additional information as to the structure of the antigens. It is probable that this polysaccharide can be purified with a less violent method than formamide extraction.

The low velocity on paper chromatograms in different solvents of most of the unknown spots pointed to the presence of disaccharides and in fact the unknown $\boldsymbol{A}$ proved to be a disaccharide consisting of glucose and galactosamine.

Chromatography on DEAE-cellulose columns shows the formamide extracts to 
be heterogeneous, though the serological specificity resided mainly in one fraction. A quantitative analysis of these purified antigens will be necessary.

A quite different approach was followed in the analysis of antigen $\mathrm{V}$, which was purified by precipitation with its homologous antibody. Here only that part of the formamide extract which reacted with antibody was analysed.

The quantitative precipitation inhibition analysis showed appreciable differences in the determinant groups of the group and type antigens.

In the system F/anti F (Fig. 1) only glucose and its $\beta$ derivatives gave good inhibition. As the inhibitions of gentiobiose (6- $\beta$-glucosido-glucose), cellobiose (4- $\beta$ glucosido-glucose) and $\beta$-methyl-glucoside were of the same level, the determinant group is probably a disaccharide with a $\beta$-glucopyranosyl group as the first sugar.

The inhibition of the I/anti I reaction as shown in Fig. 2 demonstrates that only $\mathrm{N}$-acetyl-galactosamine is important in this system. The meaning of the strong inhibition given by $\mathrm{N}$-methyl-glucamine in this and the other systems is not clear.

In the II/anti II reaction the strongest inhibition was given by $\mathrm{N}$-acetyl-galactosamine (Fig. 3). This reaction was also inhibited by N-methyl-glucamine, D-galactose and galactosamine. Here the determinant group can be composed of N-acetylgalactosamine in the first and galactose in second position, or alternatively there could be two separate determinant groups. By cross absorptions between the I and II systems it was shown! that galactose was part of a separate determinant group, specific for the II antigen.

From Fig. 4 it is clear that the determinant group of antigen III is also a $\beta$ glucosidic disaccharide. $\beta$-Methyl-glucoside gave better inhibitions than the $\alpha$ form. Gentiobiose and cellobiose gave also strong inhibitions. The second sugar of the III antigen should be different from the F antigen because the III and F systems do not give cross reactions. The possibility exists that a second determinant group containing galactose is present. The good inhibition given by galactose and melibiose (6- $\alpha$-galactosido-glucose) and not by other galactose containing oligosaccharides could point to a determinant group with an $\alpha$-galactosido-group in the first position.

The IV/anti IV system gave even more problems (Fig. 5). There was a good inhibition by galactose and its derivatives $\alpha$-methyl-galactose, 2-desoxy-galactose and lactose. The inhibition given by $\alpha$-methyl-galactose being less than that given by lactose points to a disaccharide with a $\beta$-galactosidic group. There was no evidence for the presence of a second sugar. Glucosamine + galactosamine gave better inhibition than $\mathrm{N}$-acetyl-galactosamine, while $\mathrm{N}$-acetyl-glucosamine gave no inhibition at all. This could be an argument in favour of a compound with a free amino group. The very strong inhibition by $\mathrm{N}$-methyl-glucamine might point in the same direction.

The inhibition reactions of the $\mathrm{V} /$ anti $\mathrm{V}$ system are given in Fig. 6. The $\beta$ glucosido-glucoses gave inhibitions of the same level as glucose. This finding is in contrast with the results obtained in the F/anti $F$ system where a $\beta$-glucosidolinkage in the determinant group could be demonstrated. There is no evidence about the linkage of glucose or the presence of a second sugar in the determinant group of the $\mathrm{V}$ antigen.

In all the systems tested, rhamnose and mannose were completely inactive serologically. This observation is, particularly in respect with rhamnose, in agreement with the findings of McCarty (1956) and Krause \& McCarty (1962). In the 
investigations of the group $\mathbf{A}$ and $\mathbf{C}$ streptococci these workers demonstrated a high rhamnose content of the respective polysaccharides. In their systems rhamnose was also completely inactive, except in the cases where the terminal groups of the side chains were removed (McCarty, 1956; Araujo \& Krause, 1963).

The results of the quantitative analysis (Table 2) on the one hand and the values of the $50 \%$ inhibition on the other hand (Table 4) are in broad lines in accordance with each other. However two important discrepancies in the respective results are to be relevated. The strong inhibitory effect of $\mathrm{N}$-acetyl-galactosamine in the $\mathrm{I}$ and II systems was an unexpected finding given the fact that galactosamine was only weakly represented in both polysaccharides. It is expected that purification of the antigen might bring substantial alteration in the relative sugar composition of the polysaccharide. This is shown for instance by the remarkable differences in glucose and galactose contents of the $\mathrm{V}$ antigen after its purification by means of precipitation by the homologous antibody.

We are indebted to the Netherlands Organization for the Advancement of Pure Research (Z.W.O.) for financial support for part of these studies. The able assistance of $\mathrm{Mr} \mathrm{J}$. Bours is gratefully acknowledged.

This is the first paper of a series on the immunochemistry of group F streptococci.

\section{REFERENCES}

Araujo, P. \& Krause, R. M. (1963). Group specific carbohydrate of group C-variant hemolytic streptococci. J. exp. Med. 118, 1059.

Cummins, C. S. \& Harris, H. (1956). The chemical composition of the cell wall in some gram-positive bacteria and its possible value as a taxonomic character. J. gen. Microbiol. 14, 583.

Dische, Z., Shettles, L. B. \& Osnos, M. (1949). New specific color reactions of hexoses and spectrophotometric micromethods for their determination. Archs Biochem. 22, 169.

Fuller, A. T. (1938). The formamide method for the extraction of polysaccharides from haemolytic streptococci. Br. J. exp. Path. 19, 130.

Gardell, S. (1953). Separation on Dowex 50 ion exchange resin of glucosamine and galactosamine and their quantitative determination. Acta chem. scand. 7, 207.

Gibbons, M. N. (1955). The determination of methylpentoses. Analyst, Lond. 80, 268.

HugetT, A. St G. \& Nixon, D. A. (1957). Use of glucose oxidase, peroxidase, and 0 dianisidine in determination of blood and urinary glucose. Lancet, ii, 368.

KraUSE, R. M. \& MCCARTY, M. (1962). Studies on the chemical structure of the streptococcal cell wall. II. The composition of group $\mathrm{C}$ cell walls and chemical basis for serological specificity of the carbohydrates moiety. J. exp. Med. 115, 49.

KüNDIG, W., Neukom, H. \& DeUEL, H. (1961). Untersuchungen über Getreideschleimstoffe. I. Chromatographische Fraktionierung von wasserlöslichen Weizenmehlpentosanen an Diäthylaminoäthyl-Cellulose. Helv. chim. Acta, 44, 823.

MCCARTY, M. \& LANCEFIELD, R. (1955). Variation in the group-specific carbohydrate of Group A streptococci. I. Immunochemical studies on the carbohydrates of variant strains. J. exp. Med. 102, 11.

MCCARTY, M. (1956). Variation in the group-specific carbohydrate of group A streptococci. II. Studies on the chemical basis for serological specificity of carbohydrates. J. exp. Med. $104,629$.

Michel, M. F. \& Gooder, H. (1962). Amino acids, amino sugars and sugars present in the cell wall of some strains of Streptococcus pyogenes. J. gen. Microbiol. 29, 199.

OTtENS, H. (1961). Indifferente en haemolytische streptococcen met groepsantigeen $F$. Thesis. University of Utrecht. 
OTtEns, H. \& WinkLER, K. C. (1962). Indifferent and haemolytic streptococci possessing group antigen F. J. gen. Microbiol. 28, 181.

Rondle, C. I. M. \& Morgan, W. T. I. (1955). The determination of glucosamine and galactosamine. Biochem. J. 61, 586.

Slade, H. D. \& Slamp, W. C. (1962). Cell-wall composition and the grouping antigens of streptococci. J. Bact. 84, 345.

Trevelyan, W. E., Procter, D. P. \& Harrison, I. S. (1950). Detection of sugars on paper chromatograms. Nature, Lond. 166, 444.

Winkler, K. C. \& van Amerongen, J. (1959). Bacteriological results from 4000 root canal cultures. Oral Surg. 12, 857. 